\title{
INFLUÊNCIA DA RESTRIÇÃo DA ÁGUA NA PRODUÇÃo E PESO DE OVOS
}

\author{
MSc. Diego Rene Sens - IF Baiano - Campus de Santa Inês \\ diegosens@yahoo.com.br.Msc.Alysson Soares da Rocha - IF do Tocantins - \\ Campus de Palmas soaresdarocha@ig.com.br
}

\section{RESUMO}

A constante falta de água nos bebedouros de aves poedeiras devido principalmente à falha no manejo nas granjas de produção é uma realidade que por sua vez pode resultar em queda na produção e também em mortalidade. No presente estudo, foram utilizadas 280 poedeiras da linhagem Hy Line Brown, as quais foram divididas em dois grupos: grupo controle e grupo tratamento, que por sua vez sofreu restrição hídrica num período de 7 horas a cada dois dias durante 45 dias. Os resultados evidenciaram além da mudança comportamental, a queda na produção e alterações no índice de hematócrito, sugerindo assim, que o animal sofreu alteração fisiológica.

Palavras chave: Restrição hídrica. Conversão alimentar, Hematócrito de aves.

\section{ABSTRACT}

The constant shortage of drinking water in poultry laying hens due to failure in the management of farms production is a reality which in turn can result in a decrease in production and also in mortality. In this study, we used 280 line hens Hy Line Brown, which were divided into two groups: control group and treatment group, which in turn has a water restriction period of 7 hours every two days for 45 days. The results showed than the behavioral change, the fall in production and changes in the rate of hematocrit, thus suggesting that the animal suffered physiological change

Keywords: Water restriction, Feed conversion, Hematocrit of birds.

\section{INTRODUÇÃO}

Aágua é o nutriente requerido em maior quantidade para as aves e, segundo HARRIS JUNIOR et al. (1975), deveria ser considerado o nutriente essencial mais importante. É a substância mais abundante nos sistemas vivos, e a porcentagem de água do corpo depende de fatores como a espécie, a quantidade de gordura e a idade do animal. Para galinhas, a quantidade de água corpórea em porcentagem do peso total de animais adultos corresponde a 53\% (PIZAURO JÚNIOR, 1996). No entanto, devido às falhas de manejo e falta de estrutura, a falta de água nos bebedouros é um problema comum.

A restrição de água propicia uma redução no consumo de alimento (BROOKS, 1994). Esta redução no consumo consequentemente resulta em redução do desempenho das aves. Quando a água é oferecida à vontade, a ave desenvolve um padrão bem característico de ingestão de alimento. Por outro lado, esse padrão pode ser alterado de acordo com a disponibilidade e o manejo da água (MACARI, 1995). Poedeiras com restrição de água por 24 horas, podem demorar ate 3 semanas para recuperar seu índice de postura anterior (MACARI, 1995). A restrição de água pode causar um aumento da freqüência cardíaca, da freqüência respiratória, da temperatura retal, da dormência e/ou ardor nas extremidades, um aumento na concentração sanguinea. Aves sem acesso à água, até mesmo por poucas 
horas, especialmente em ambientes quentes, interrompem o crescimento e podem apresentar maior susceptibilidade a doenças (Nilipour \& Butcher, 1998). A água influencia ainda a saúde e o bem estar dos animais.

Segundo Soares et al. (2007), os dados de hematócrito são parâmetros adequados de avaliação da desidratação em frangos de corte, sem contar que este parâmetro é de fácil mensuração e pode ser realizado dentro da propriedade rural. Esta medida do hematócrito permite avaliação prática e rápida do estado geral dos animais, porém pode apresentar variação severa em casos de desidratação, pois há hemoconcentração (JAIN, 1986; THRALL, 2004).

Este trabalho foi realizado com o objetivo de avaliar a produção e peso de ovos de galinhas submetidas a restrições hídrica de 7 horas a cada dois dias num período de 45 dias. $\mathrm{O}$ índice de hematócrito foi utilizado como marcador das condições fisiológicas do animal.

\section{MATERIAIS E MÉTODOS}

O experimento foi conduzido no Setor de Avicultura do Departamento de Zootecnia I do Instituto Federal de Educação, Ciência e Tecnologia - IFET, Campus de Araguatins, município de Araguatins, Tocantins. Foram utilizadas 280 poedeiras da linhagem Hy Line Brown distribuídas em um delineamento inteiramente casualizado, com dois tratamentos, sendo um grupo tratamento e outro grupo controle, em dez repetições e quatro aves por unidade experimental. As poedeiras foram alojadas em gaiolas de arame com dimensões de $25 \mathrm{~cm} \times 37 \mathrm{~cm} \times 41 \mathrm{~cm}$, com programa de luz natural e água à vontade. As aves foram alimentadas duas vezes no dia, as 9 e $15 \mathrm{~h}$, com ração comercial para aves de postura, em quantidade de $110 \mathrm{~g} /$ ave/dia.

O período experimental foi de 55 dias, sendo 10 dias para aclimatação das aves nas novas gaiolas experimentais e 45 dias de experimento. Durante os 45 dias o fluxo de água para os bebedouros foi fechado no período das 8 às 15 horas ( 7 horas de restrição) a cada dois dias. As aves foram pesadas no início do experimento para padronização do peso por unidade experimental. Diariamente, os ovos de cada parcela foram contados e os registros anotados em formulário próprio. Além disso, foram avaliados o consumo de ração (g/ave/ dia), e uma vez por semana, os ovos de cada parcela foram pesados. Ao final de cada dia, foram coletadas as sobras de rações de cada parcela para o cálculo do consumo de ração e da conversão alimentar de cada tratamento. A coleta dos ovos foi realizada duas vezes ao dia (10 e 16h) para registro da freqüência de postura, do número de ovos intactos e defeituosos e da possível mortalidade das aves. A produção dos ovos foi calculada em porcentagem dividindose a quantidade de ovos produzidos por parcela pelo número de aves.

Para estudar o percentual de hematócrito, o sangue foi coletado da veia braquial de uma ave de cada repetição (10 aves/tratamento), com o auxílio de seringas heparinizadas aos 35 e 45 dias de experimento. A determinação do hematócritos $(\mathrm{Hct}=\%)$ foi realizada em réplicas utilizando-se o método de microhematócrito em tubo capilar de $75 \mathrm{~mm}$, selado em uma das extremidades e centrifugado por 6 minutos a $12000 \mathrm{rpm}$ em uma centrífuga de microhematócrito FANEM, modelo 207/N. A proporção entre a parte sólida (eritrócitos e leucócitos) e líquida (plasma) do sangue de cada amostra foi estimada em percentagem com o auxílio de um cartão de leitura padronizado.

Foi adotado um tratamento inteiramente casualizado, sendo dois tratamento com dez repetições cada. Para análises dos resultados, os dados foram submetidos ao teste de Bartlett, para averiguação da homogeneidade das variáveis, seguidas pelo "teste T" de Student, para comparação entre as médias. Foram considerados significativos valores de $\mathrm{P}<0,05$. Todos os cálculos foram realizados utilizando o software estatístico Graph Pad Prism version 
3.0 for Windows, San Diego-Califórnia, EUA.

\section{RESULTADOS E DISCUSSÃO}

As aves em restrição de água apresentaram-se alterados comportamentalmente durante o período experimental. Nos períodos em que as aves estavam sem água, elas não ingeriam alimento e procuravam manter-se em estado de repouso, apresentando sonolência. Estas alterações comportamentais só foram registradas nas aves do grupo tratamento.

De acordo com Lloyd et al. (1978), a restrição de água pode causar um aumento na freqüência cardíaca, da freqüência respiratória, da temperatura retal, maior dificuldade de circulação sanguinea e consequentemente dormência no corpo. Estes efeitos podem levar a conseqüências secundarias como a falta de apetite, reduzindo consequentemente a ingestão de alimento pela ave.

A ingestão de ração foi visualmente afetado pela restrição de água sofrida pelos animais do grupo tratamento (Tabela 1). Os resultados de ingestão de ração estão de acordo com os observados por Kellerup et al. (1965) que verificaram uma queda no consumo de alimento em resposta às restrições progressivas de água. Para cada espécie animal existe uma relação entre o consumo de água e a ingestão de alimento. Na prática, uma regra para o consumo de água de aves de produção é que ela é o dobro do consumo de ração (LlOYD et al, 1978).

Em relação aos dados de conversão alimentar, percebe-se a sua redução significativa ocorrida provavelmente pela restrição hídrica e consequente queda na ingestão de ração. A conversão alimentar apresentou resultados cada vez mais inferiores de acordo com o andar do experimento. Este fato pode ser explicado pelo aumento da necessidade da mantença, não proporcionando um ganho de peso suficiente, $\mathrm{e}$ a ave se alimenta mais para a mantença do que para o ganho de peso.
Kellerup et al. (1965), não encontraram diferenças na conversão alimentar de frangos de corte submetidos a uma restrição de $10 \%$ de água. Já para as restrições de 20 e $30 \%$, as diferenças só foram significativas a partir da sétima semana e com as restrições de 40 e $50 \%$ as diferenças se manifestaram a partir da quarta semana de idade. Os autores concluíram ainda que a ave não consegue sobreviver por muito tempo na ausência completa de água.

TABELA 1 - Porcentual de hematócrito sanguineo de aves submetidas à restrição hídrica ${ }^{(1)}$.

\begin{tabular}{ccc}
\hline Parâmetro & \multicolumn{2}{c}{ Condição } \\
\hline & Controle & Tratamento \\
\cline { 2 - 3 } Produção de ovos & $90,6 \%$ & $34 \%$ \\
Peso dos ovos $(\mathrm{g})$ & $60,9 \pm 3,57$ & $59,8 \pm 2,98$ \\
Ingestão de alimento $(\mathrm{g} / \mathrm{dia})$ & $113,6 \pm 8,32$ & $89,35 \pm 14,87$ \\
Conversão alimentar & 1,50 & 3,78 \\
\hline (1) Letras maiúsculas comparam o mesmo tratamento no início e \\
final do período experimental. Letras minúsculas comparam os \\
tratamentos no mesmo momento testado. Valores considerados \\
diferentes estatisticamente quando $\mathbf{p}<\mathbf{0 , 0 5 .}$
\end{tabular}

$\mathrm{Na}$ primeira coleta, aos 35 dias, os animais do grupo controle e do grupo tratamento apresentaram hematócrito de $33,11 \%$ e $34,8 \%$ respectivamente. Após o período de 10 dias o hematócrito do grupo controle baixou para $32,9 \%$ e o grupo tratamento aumentou para $35,1 \%$. Este aumento verificado nos animais do grupo tratamento em relação ao grupo controle, além da hemoconcentração, pode ser explicado também pela ação do cortisol induzido pelo estresse crônico provocado pela situação de falta de água.

Tabela 2 - Porcentual de hematócrito sanguineo de aves submetidas à restrição hídrica ${ }^{(1)}$.

\begin{tabular}{rcc}
\hline \multicolumn{1}{c}{ Parâmetro } & \multicolumn{2}{c}{ Condição } \\
\hline Hematócrito (\%) & Controle & Tratamento \\
\cline { 2 - 3 } 35 dias & $33,1 \pm 1,27^{\mathrm{a}}$ & $34,8 \pm 1,27^{\mathrm{b}}$ \\
45 dias & $32,9 \pm 1,43^{\mathrm{a}}$ & $35,1 \pm 1,50^{\mathrm{b}}$ \\
\hline
\end{tabular}

(1) Letras maiúsculas comparam o mesmo tratamento no início e final do período experimental. Letras minúsculas comparam os 
tratamentos no mesmo momento testado. Valores considerados diferentes estatisticamente quando $\mathbf{p}<\mathbf{0 , 0 5}$.

\section{CONCLUSÕES}

Os resultados obtidos no presente experimento evidenciaram além das mudanças comportamentais e no hematócrito, a queda na produção devido à ausência da ingestão alimentar.

\section{BIBLIOGRAFIA}

BROOKS, P.H. Water- Forgotten nutrient and novel delivery system. In: ALLTECH'S ANNUAL SYMPOSIUM, 10, 1994. Ganswill. Biotechnology in the Feed Industry. Nottingham: Nottingham University Press, 1994. p 211-234.

JAIN, N.C. Schalm's - Veterinary Hematology. $4^{\mathrm{a} E d}$., Philadelphia: Lea \& Febiger,1221p. p. 589-626. 1986.

KELLERUP, S.U.; PARKER, J.E.; ARSCOTT, G.H.; Effect of restricted water consumption on broiler chickens. Poultry Science, Champaing, v. 44, n.1, pag. 79-83, 1965.

LLOYD,L.E.; McDONALD,B.E.;CRAMTON, E,W, Fundamentals of nutrition: Water and its metabolism. San Francisco: W.H. Freeman and Company, 1978. pag. 22-35.

MACARI, M. Metabolismo hídrico da poedeira comercial. In: SIMPOSIO TÉCNISO DE PRODUÇÃO DE OVOS. 5. 1995, Jaboticabal, Resumos. Jaboticabal: APA. P 109-131.

NILIPOUR, A.H.; BUTCHER, G.D. Water: the cheap, plentiful and taken for granted nutrient. World Poultry, v.14, n.1, p.26- 27, 1998.

SOARES, L.F.; RIBEIRO, A.M.L.; JUNIOR, A.M.P.; GHIOTTI, A. Influência da restrição de água e ração durante a fase pré-inicial no desempenho de frangos de corte até os 42 dias de idade. R. Bras. Zootec., v.36, n.5, p.15791589, 2007.

THRALL, A.M. Veterinary Hematology stand Chemical Chemistry Ed. Philadelphia: Lippincott Willams \& Wilkins, 518p., p.301328. 2004. 